\title{
Distinct roles for P-CREB and LEF-1 in TCR $\alpha$ enhancer assembly and activation on chromatin templates in vitro
}

\author{
Timothy P. Mayall, ${ }^{1}$ Philip L. Sheridan, ${ }^{1}$ Marc R. Montminy, ${ }^{1,2}$ and Katherine A. Jones ${ }^{1,3}$ \\ ${ }^{1}$ The Salk Institute for Biological Studies, La Jolla, California 92037-1099 USA
}

\begin{abstract}
The distal enhancer of the T-cell receptor (TCR) $\alpha$ chain gene has become a paradigm for studies of the assembly and activity of architectural enhancer complexes. Here we have reconstituted regulated TCR $\alpha$ enhancer activity in vitro on chromatin templates using purified T-cell transcription factors (LEF-1, AML1, and Ets-1) and the cyclic AMP-responsive transcription factor CREB. When added in combination, these factors activate the TCR $\alpha$ enhancer in a highly synergistic manner. Alternatively, the enhancer could also be activated in vitro by high levels of either CREB or a complex containing all of the T-cell proteins (LEF-1, AML1, and Ets-1). Phosphorylation of CREB by protein kinase $A$ enhanced transcription 10-fold in vitro, and this effect was abolished by a point mutation affecting the CREB PKA phosphorylation site (Ser-133). Interestingly, LEF-1 strongly enhanced the binding of the AML1/Ets-1 complex on chromatin, but not nonchromatin, templates. A LEF-1 mutant containing only the HMG DNA-binding domain was sufficient to form a higher-order complex with AML1/Ets-1, but exhibited only partial activity in transcription. We conclude that the $T$ cell-enriched proteins assemble on the enhancer independently of CREB and function synergistically with CREB to activate the TCR $\alpha$ enhancer in a chromatin environment.
\end{abstract}

[Key Words: CREB; LEF-1; AML1; Ets-1; T-cell transcription factors; TCR $\alpha$ enhancer; chromatin]

Received January 24, 1997; revised version accepted February 28, 1997.

Appropriate regulation of the T-cell receptor $\alpha$ (TCR $\alpha$ ) enhancer during $\mathrm{T}$-cell development requires the assembly of a stereospecific nucleoprotein complex that is capable of regulating transcription over large genomic distances in a lineage- and developmental stage-specific manner. Within a tightly arranged compact core, the minimal TCR $\alpha$ enhancer (Ho et al. 1989; Winoto and Baltimore 1989) has maintained closely juxtaposed binding sites for three distinct $\mathrm{T}$ cell-enriched transcription factors (LEF-1, AML1, and Ets-1) near a single binding site for members of the cAMP response element binding (CREB)/activating transcription factor (ATF) family (Ho and Leiden 1990; Travis et al. 1991; Waterman et al. 1991; Giese et al. 1995). The T lymphoid enhancer-binding proteins that regulate the $\operatorname{TCR} \alpha$ enhancer are expressed at relatively high levels in resting adult $\mathrm{T}$ lymphocytes, although each displays a widely divergent pattern of expression in other tissues and cell lineages at earlier stages in mammalian development (Oosterwegel et al. 1993; Van Genderen et al. 1994; Satake et al. 1995). The lymphoid enhancer-binding protein LEF-1 (Travis et al. 1991; Waterman et al. 1991) is a member of the high

\footnotetext{
${ }^{2}$ Present address: The Joslin Diabetes Center, Harvard University, Boston, Massachusetts 02215 USA.

${ }^{3}$ Corresponding author.

E-MAIL kathy_jones@qm.salk.edu; FAX (619) 535-8194.
}

mobility group (HMG) protein family that induces a characteristic sharp bend in the DNA helix upon binding to the enhancer (Giese et al. 1992). We and others have shown that LEF-1 can activate transcription in vitro only in conjunction with other enhancer-binding proteins (Carlsson et al. 1993; Giese and Grosschedl 1993). Within the specific context of the TCR $\alpha$ enhancer, LEF-1 has been proposed to behave as an architectural transcription factor that facilitates the assembly of proteins bound to neighboring sites (Grosschedl et al. 1994). Transcriptional activation by LEF-1 is more complex, however, because it contains an essential transcriptional activation domain that is separate from the HMG box (Carlsson et al. 1993; Giese and Grosschedl 1993). Furthermore, the LEF-1 activation domain retains its context-restricted activity even when fused to a heterologous (non-HMG) DNA-binding domain (Carlsson et al. 19931, indicating that LEF-1 must also participate actively in steps distinct from enhancer assembly.

Somewhat less is known of the precise role of the AML1 and Ets-1 proteins in the regulation of TCR $\alpha$ enhancer activity in vivo. AML1 (also called PEBP2/CBF; for review, see Kagoshima et al. 1993) is a heterodimeric transcription factor complex composed of a DNA-binding $(\alpha)$ subunit that is a homolog of the Drosophila pairrule runt gene family and a regulatory $(\beta)$ subunit that increases the DNA-binding affinity of the complex (Miyoshi et al. 1993; Ogawa et al. 1993a,b; Wang and Speck 
1993|. AML1 plays an important role in the development of the hematopoietic lineage and is a frequent target of chromosomal rearrangements in human leukemias (Miyoshi et al. 1991; Liu et al. 1993; Okuda et al. 1996). The AML1 proteins bind to enhancer core elements of a large number of different hematopoietic-specific genes, including all of the characterized TCR antigen genes, and have been shown by means of targeted gene disruption in transgenic mice to be essential for the development of definitive hematopoesis of all lineages (Okuda et al. 1996). Residues carboxy-terminal to the runt homology domain in certain AML1 family members are critical for transcriptional activation (Bae et al. 1994); however, it is not clear that this region constitutes an independent modular trans-activation domain. AMLl has been proposed to function as a transcriptional organizer to recruit lineage-specific transcription factors, most commonly the lymphoid-specific Ets-1 and c-Myb proteins (Hernandez-Munain and Krangel 1994; Wotton et al. 1994; Giese et al. 1995). AML1 binds in a highly cooperative manner with Ets-1 to the TCR $\alpha$ (and TCR $\beta$ ) enhancer in vitro, and mutations affecting either the Ets-1- or AML1-binding sites are equally disruptive to TCR $\alpha$ enhancer activity in vivo (Wotton et al. 1994; Giese et al. 1995). These observations suggest that these two factors act synergistically, perhaps by combining to present a unique activation surface for interactions with neighboring enhancer-binding proteins or downstream transcriptional coactivators.

Recent DNA-binding and protein association studies have led further to the proposal that bending of the DNA by LEF-1 serves to facilitate protein-protein interactions between Ets-1 and specific isoforms of the ATF protein family that can bind to the TCR $\alpha$ enhancer CRE motif (Giese et al. 1995). In particular, it was shown that recombinant Ets-1 can interact by Far Western blotting with ATF2 ${ }_{194}$, an isoform of ATF2 that lacks part of the ATF dimerization domain, but not with the (dimeric) ATF $2_{195}$ isoform or with CREB. In the model suggested by these studies, bending of the DNA by LEF-1 would serve to facilitate protein-protein interactions between very specific members of the ATF and Ets transcription factor families bound to the distal ends of the enhancer. Because recombinant forms of these proteins could not be shown to generate stable enhancer complexes in DNase I footprint experiments, it was further suggested that the TCR $\alpha$ enhancer-binding proteins might need to be modified or interact with other (non-DNA-binding) proteins to support enhancer assembly (Giese et al. 1995).

To further elaborate the molecular mechanisms that underly synergistic activation of the minimal TCR $\alpha$ enhancer, we sought to reconstitute enhancer activity in vitro using purified enhancer-binding proteins and an in vitro nucleosome-assembly system that can mobilize nucleosomes in an ATP-dependent manner to permit transcription factor access and function in vitro (Kamakaka et al. 1993; Bulger and Kadonaga 1994; Pazin et al. 1994; Tsukiyama et al. 1994). We have demonstrated previously that this approach can be used to study the regulation of HIV-1 transcription by LEF-1 and other en- hancer-binding proteins (Sheridan et al. 1995; Pazin et al. 1996), and indeed transcriptional activation by LEF-1 in vitro was detected only with chromatin templates in these studies. These studies revealed that LEF-1 could activate the HIV-l enhancer only in the presence of Ets-1 (or other enhancer-binding proteins), and that the LEF-1 trans-activation domain was critical for HIV-1 enhancer activity in vitro (Sheridan et al. 1995). Here we examine the role of LEF-1 and other enhancer-binding proteins in the assembly and activation of the TCR $\alpha$ enhancer in vitro. Our findings suggest a new model for TCR $\alpha$ enhancer assembly and function that is dictated by the natural arrangement of transcription factor binding sites as well as by the chromatin environment.

\section{Results}

Phosphorylation of CREB by protein kinase A enhances TCR $\alpha$ enhancer activity in vivo and in vitro

As shown in Figure 1A, the core domain of the TCR $\alpha$ enhancer contains closely juxtaposed binding sites for the T-cell enriched transcription factors, LEF-1, AML1, and Ets-1, separated at a short distance from a CRE motif. This particular arrangement of transcription factor binding sites appears to be critical for enhancer activity in vivo; for example, the enhancer is inactivated if the LEF-1 binding site is moved out of this context and placed distal to the AML1/Ets-1 composite element (Giese et al. 1995). To examine the molecular basis underlying the synergistic activation of the TCR $\alpha$ enhancer, we sought to define conditions under which recombinant proteins would support TCR $\alpha$ enhancer activity in vitro using nucleosome-assembled DNA templates.

Because a wide variety of CRE-binding proteins exist in $\mathrm{T}$ cells, it was important first to establish the identity of the relevant CRE-binding proteins that interact with the TCR $\alpha$ enhancer in T cells. Analysis of the proteins bound to the TCR $\alpha$ enhancer CRE motif in fractionated extracts from the Jurkat $T$-cell line revealed the presence of both CREB as well as CREBP1/ATF2 and other ATFrelated proteins (data not shown). Addition of CREB-specific antisera affected approximately one-half of the specific binding complexes that were detected in gel mobility shift experiments with Jurkat cell nuclear extract, indicating that CREB is a likely regulator of the TCR $\alpha$ enhancer in vivo. To test this possibility directly, transient expression experiments were carried out to evaluate whether the TCR $\alpha$ enhancer is responsive to protein kinase A (PKA), which has been shown to phosphorylate CREB and strongly potentiate its transcriptional activity in vivo (Yamamoto et al. 1988; Gonzales and Montminy 1989; Gonzales et al. 1991). For these experiments, we generated two reporter gene constructs, pTCR $\alpha 1 \mathrm{tk}$ and pTCR $\alpha 2 \mathrm{tk}$, which contain a single and a duplicated copy of the TCR $\alpha$ enhancer, respectively, cloned upstream of a heterologous promoter and the luciferase reporter gene (Materials and Methods). As shown in Figure 1B, cotransfection of either pTCR $\alpha 1$ tk or pTCR $\alpha 2$ tk with a con- 
A

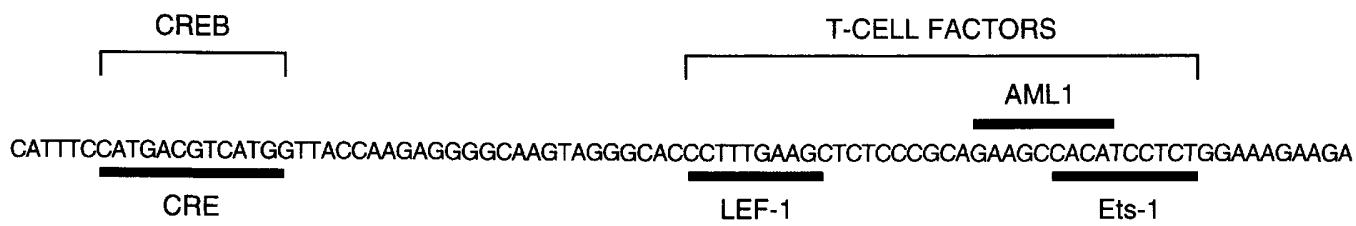

B
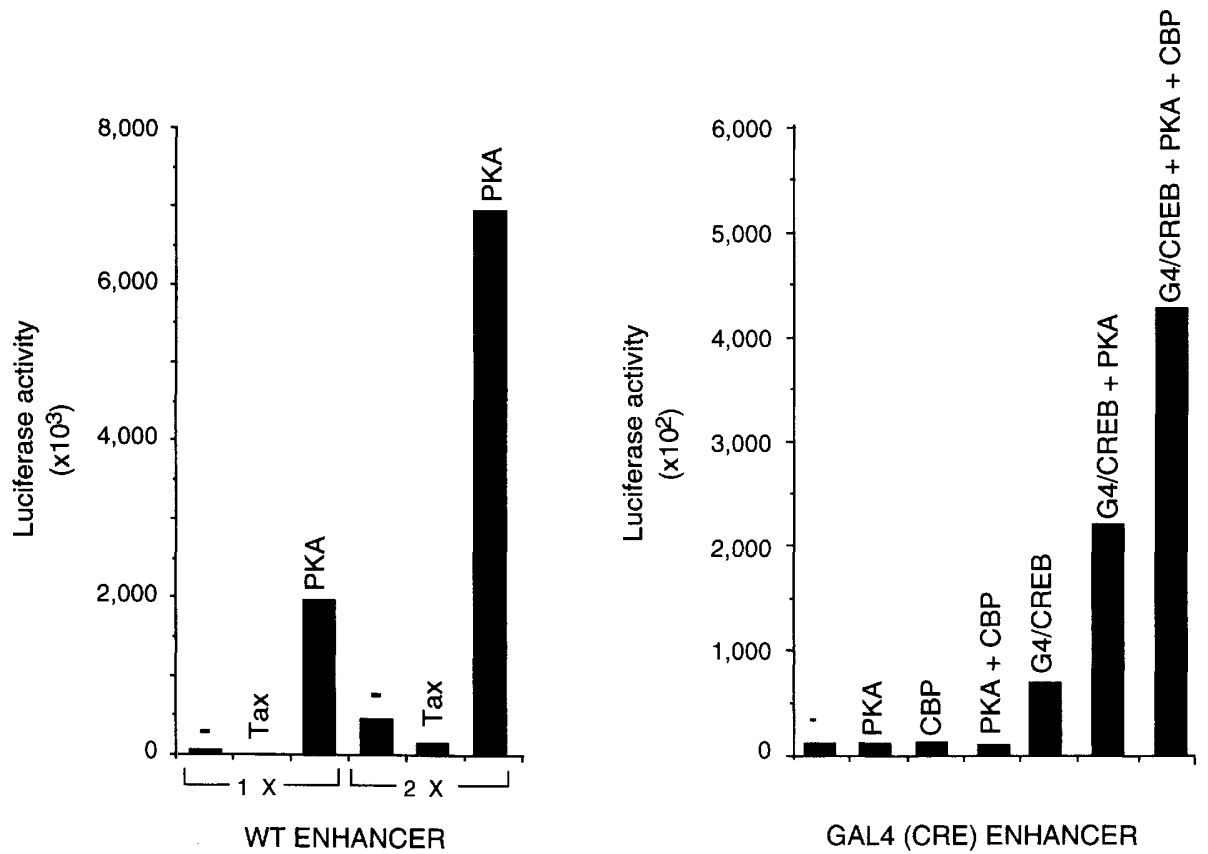

Figure 1. Expression of protein kinase A stimulates CREB-mediated activation of the TCR $\alpha$ enhancer in Jurkat $(T)$ cells. $(A)$ Relative location of CREB, LEF-1, and AML1/Ets-1 binding sites within the core region of the TCR $\alpha$ enhancer. $(B)$ PKA expression activates the TCR $\alpha$ enhancer in vivo. Transient expression assays were carried out in TPA-stimulated Jurkat cells using vectors that contain either one or two copies of the 115-bp core region of the human TCR $\alpha$ enhancer positioned upstream of the luciferase reporter gene (TCR $\alpha 1$ tk or TCR $\alpha 2$ tk; Carlsson et al. 1993). Vector DNAs were transfected alone (-) or in conjunction with either a PKA expression vector (pMT/PKA) or a vector that expresses the HTLV-I Tax protein (pCMV/Tax) (bottom, left). (Right) The TCR $\alpha$ CRE motif was replaced with the DNA-binding site for GAL4. This vector was tested alone (-) or in the presence of the different expression vectors, as indicated above each bar. The GAL4/CREB chimeric activator contains the GAL4 DNA-binding domain fused to the transactivation domain of CREB (Brindle et al. 1993). Luciferase activity was calculated as the mean of duplicate samples from a single representative transfection experiment and was normalized to a pCMV-CAT plasmid that was cotransfected as an internal control (Materials and Methods).

struct that expresses PKA increased TCR $\alpha$ enhancer activity by greater than 20 -fold in Jurkat $\mathrm{T}$ cells. By contrast, the enhancer was not activated by the HTLV-I Tax protein, which can activate CREB only when it is bound within the context of the CRE motifs of the HTLV-I enhancer (Fig. 1B). Substitution of the CRE motif in the $\mathrm{TCR} \alpha$ enhancer with a single binding site for the yeast GAL4 activator eliminated activation by PKA, confirming that the effect of PKA was mediated through the CREB binding site (Fig. 1C). We further determined that the GAL4-substituted TCR $\alpha$ enhancer is responsive to GAL4/CREB, a chimeric protein that contains the transactivation domain of CREB fused to the DNA-binding domain of the yeast GAL4 protein. As expected, GAL4/ CREB activity in vivo was further stimulated upon coexpression of PKA. Expression of CBP, a transcriptional coactivator that binds specifically to the PKA-phosphorylated form of CREB and mediates transcriptional activation by cAMP and numerous other signaling pathways (Chrivia et al. 1993; Arany et al. 1994; Arias et al. 1994; Kwok et al. 1994; Chakravarti et al. 1996) further increased GAL4/CREB activity in vivo (Fig. 1B). Taken together, these data strongly implicate CREB as a potent PKA-responsive activator of the TCR $\alpha$ enhancer in vivo.

To examine the ability of CREB to activate the TCR $\alpha$ enhancer in vitro, both nonphosphorylated and phosphorylated forms of recombinant CREB were incubated with TCR $\alpha$ enhancer DNA (pTCR $\alpha$ ) during nucleosome assembly, and the chromatin templates were analyzed by in vitro transcription with HeLa nuclear extracts. Transcription from naked DNA plasmids containing the $\alpha$-globin gene was used as an internal control for RNA recovery in this system. In these experiments, CREB was either phosphorylated with purified protein kinase $A$ or mock-treated by incubation in parallel with kinase 
buffer lacking protein kinase A. Both the phosphorylated and nonphosphorylated (mock-treated) CREB proteins were then incubated with the protein kinase A inhibitor $\mathrm{PKi}$, and added to the nucleosome assembly reaction together with the DNA template. As shown in Figure 2A, incubation of the TCR $\alpha$ enhancer plasmid with relatively high levels of nonphosphorylated CREB during nucleosome assembly was sufficient to activate the enhancer 20-fold even in the absence of other enhancerbinding proteins. Phosphorylation of CREB by PKA strongly increased its transcriptional activity in vitro (Fig. 2A). PKA phosphorylation also increased CREB activity 10 -fold when it was used at suboptimal levels in this system (Fig. 2B). Both phosphorylated and nonphosphorylated forms of CREB were capable of acting synergistically with Spl bound at the promoter (Fig. 2B). By contrast, PKA had no effect on transcription in the absence of CREB, either when it was tested alone or in the presence of Sp1 (Fig. 2B,C). Phosphorylation of CREB by PKA did not affect its ability to bind to the chromatin templates in DNase I footprint experiments (Fig. 2D), consistent with its failure to affect binding of CREB to naked DNA.

To determine whether the PKA effect was mediated through phosphorylation of Ser133 within the CREB activation domain, we tested a mutant CREB protein (CREBM1) containing a single amino acid substitution in the PKA phosphorylation site (Ser-133 to Ala-133). Although CREBM1 could be shown to bind DNA and stimulate transcription 10 -fold from the enhancer, its activity was not enhanced by incubation with protein kinase A (Fig. 2C). DNA-binding experiments revealed that both the wild-type and CREBMl proteins bound efficiently to the TCR $\alpha$ enhancer in these experiments (Fig. 2D). Taken together, these results indicate that phosphorylation of CREB by PKA strongly enhances its transcriptional activity on chromatin in vitro through a mechanism that does not affect its ability to access its site on nucleosomal DNA.

\section{The T-cell factors act in a combinatorial manner to activate the TCR $\alpha$ enhancer in vitro}

The T-cell specificity of the TCR $\alpha$ enhancer is conferred by three adjacent sites that bind lymphoid cell transcription factors (LEF-1, AML1, and Ets-1), and mutations in any of these protein-binding sites eliminate enhancer activity in vivo (Giese et al. 1995; T. Mayall, unpubl.). Purified recombinant forms of each of these proteins were used to assess their ability to act, individually and collectively, to derepress nucleosome-assembled TCR $\alpha$ enhancer DNA in vitro. Unlike CREB, which could activate the TCR $\alpha$ enhancer in the absence of other enhancer-binding proteins, none of the individual $\mathrm{T}$-cell enhancer-binding proteins were able to act on their own to enhance transcription from the chromatin templates (data not shown). Instead, the T-cell proteins acted only in concert with each other, or in combination with CREB or the promoter-binding protein Spl. To assess the transcriptional activity of the lym-
Figure 2. Phosphorylation by protein kinase A enhances CREB activity on nucleosome-assembled TCR $\alpha$ enhancer DNA in vitro. $(A)$ Comparison of the relative abilities of nonphosphorylated and PKA-phosphorylated CREB to activate the TCR $\alpha$ enhancer in vitro. Purified CREB (120 nM) was phosphorylated by incubation with purified protein kinase $A$, and PKA was subsequently inactivated by incubation with PKi prior to addition of the CREB to the nucleosome assembly reactions. The nonphosphorylated CREB (120 nM) was treated in parallel with buffers lacking PKA, as described in Materials and Methods. $(B)$ Phosphorylated CREB activates transcription synergistically with Spl. In this experiment, suboptimal levels of nonphosphorylated or PKA-phosphorylated CREB (50 nM) were analyzed, alone and in combination with $20 \mathrm{nM} \mathrm{Spl}(C)$ Mutation of CREB Ser133 abolishes regulation by PKA in vitro. The purified proteins that were incubated with the template during chromatin assembly are indicated above each of the duplicate lanes. CREBMl contains a point mutation (Ser-133 to Ala-133) within the PKA phosphorylation site. (D) DNase I footprint analysis of the binding of CREB and CREBM1 proteins to the same chromatin templates that were analyzed for transcriptional activity in $C$.
A
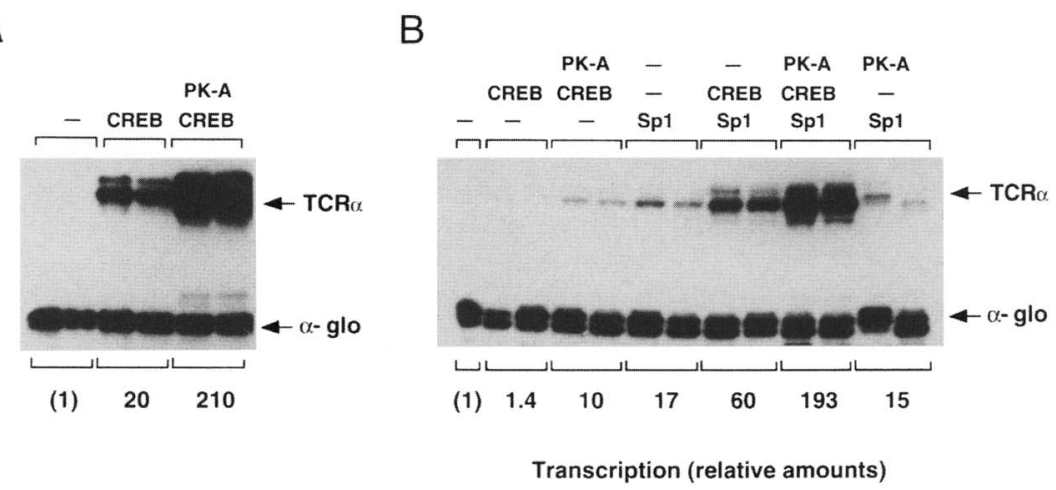

C

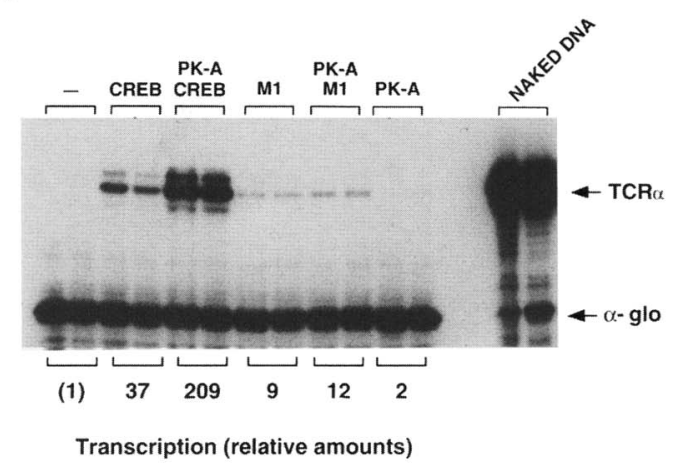


phoid factors in the absence of CREB, we examined the ability of each protein to augment Sp1-driven (basal) transcription. As shown in Figure 3, each of the three T-cell factors could activate the enhancer when incubated at high levels with the DNA in the presence of $S p l$ during nucleosome assembly. The level of activation seen with LEF-1 and Ets-1 in these assays was comparable to that we observed previously using HIV-1 enhancer chromatin templates, which bind LEF-1 and Ets-1 but not AML1 (Sheridan et al. 1995).

The AML1 protein used in these studies was recombinant AML1B, a human homolog of the $\alpha$ subunit of the murine DNA-binding protein PEBP2/CBF, which has been shown previously to be transcriptionally active in vivo (Meyers et al. 1995). As AML1B normally functions as a complex with a non-DNA-binding $(\beta)$ subunit $(\mathrm{Mi}-$ yoshi et al. 1993; Ogawa et al. 1993a,b; Wang and Speck 1993), we also expressed and purified the beta subunit of PEBP2 for these studies. As shown in Figure 3, AML1B (PEBP2 $\alpha$ subunit) was capable of activating the enhancer when incubated with DNA in the presence of Spl, and its activity was further enhanced upon addition of the $\beta$ (non-DNA-binding) subunit (PEBP $\beta 2$; Kagoshima et al. 1993). In gel mobility shift experiments, the $\beta$ subunit enhanced the binding affinity of AML1 and altered the mobility of the AML1 protein-DNA complex, and both proteins bound cooperatively with recombinant Ets-1 to the TCR $\alpha$ enhancer, as expected (data not shown). Consistent with its ability to enhance the DNA-binding activity of the AML1 complex, addition of Ets-1 to AML1 increased transcription in vitro, and the overall activity of these two proteins was enhanced dramatically upon the subsequent addition of LEF-1 (Fig. 3). These data show that although the core TCR $\alpha$ enhancer factors have

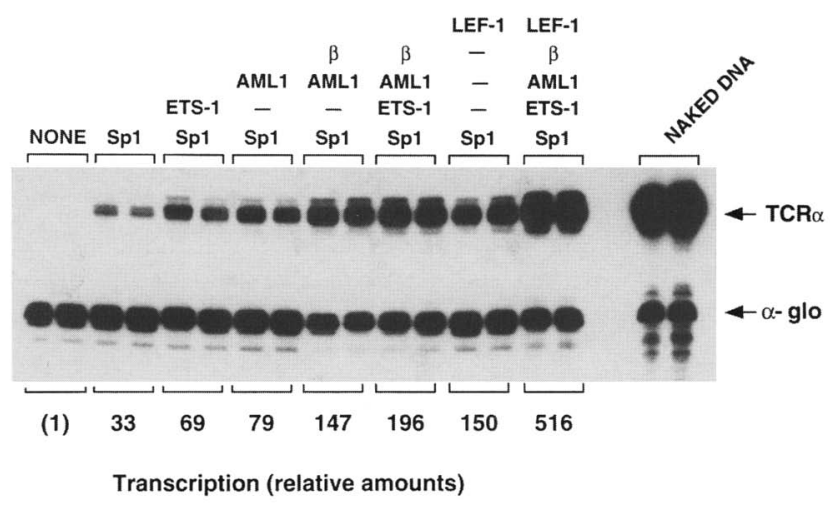

Figure 3. Nucleosome-assembled TCR $\alpha$ enhancer DNA is strongly activated by a combination of the $\mathrm{T}$-cell transcription factors LEF-1, AML1, and Ets-1. The individual purified T-cell factors were analyzed in the presence of $\mathrm{Spl}$, as indicated above each lane. The purified enhancer-binding proteins were incubated with the TCR $\alpha$ enhancer DNA prior to nucleosome assembly. The transcriptional activity of AML1 was assayed by using the DNA-binding subunit (AML1B) alone or in combination with the $\beta$ (regulatory) subunit (PEBP2 $\beta 2$ ), as indicated above the lanes. In all subsequent figures, AML1 was added as a combination of both subunits. weak activity when assayed individually, they can be potent activators of transcription when present in combination. We conclude that the T-cell proteins act in a combinatorial manner to stimulate transcription, and that at saturating levels they can activate the TCR $\alpha$ enhancer independently of CREB.

\section{Reconstitution of TCR $\alpha$ enhancer activity in vitro with CREB and T-cell enhancer-binding proteins}

To reconstitute the activity of the complete TCR $\alpha$ enhancer, we carried out a series of experiments using suboptimal levels of P-CREB and various combinations of the individual T-cell enhancer-binding proteins. For this and all subsequent experiments here, the AML1 protein was bound to DNA as a complex containing both $A M L 1 B$ and PEBP $\beta 2$ proteins. Under the conditions where the TCR $\alpha$ enhancer-binding proteins are present at limiting concentrations, the TCR $\alpha$ enhancer was activated only modestly by phosphorylated CREB or by the combination of T-cell transcription factors. By contrast, the combination of P-CREB with the T-cell proteins resulted in highly synergistic activation of transcription from the enhancer (Fig. 4B). Addition of Sp1 further augmented transcription in this system, resulting in a 100 fold increase in RNA levels over that seen with the fully repressed chromatin template that had not been incubated with enhancer-binding proteins during nucleosome assembly. DNase I footprint experiments using these chromatin templates revealed that each protein bound specifically to its site on the enhancer (Fig. 1C), and we confirmed that mutations affecting either the CREB or T-cell factor-binding sites eliminated the ability of these factors to activate the enhancer in vitro (data not shown). Taken together with the results presented above, these data indicate that CREB and the T-cell transcription factors are capable of assembling a functional nucleoprotein complex that mediates strong synergistic activation of the TCR $\alpha$ enhancer in vitro.

We next examined how the binding of these regulatory proteins influences the local chromatin structure surrounding the TCR $\alpha$ enhancer on the nucleosomal DNA templates. Because we were interested in the specific influence of the assembled nucleoprotein complex on the distribution of nucleosomes near the enhancer, these experiments were performed in the absence of HeLa nuclear extract to eliminate any structural changes that might occur subsequent to transcription. As shown in Figure 5A, binding of Spl and phosphorylated CREB specifically disrupted the nucleosome array in the vicinity of the pTCR $\alpha$ enhancer. Similar results were obtained using a combination of LEF-1, AML1, and Ets-1 (data not shown). In contrast, none of these proteins affected the nucleosome assembly of bulk chromatin in regions distal to the enhancer, as evidenced by hybridization of a micrococcal nuclease digestion ladder with a radiolabeled DNA probe located $\sim 1000 \mathrm{bp}$ upstream of the TCR $\alpha$ enhancer (Fig. 5A). Binding of CREB to the chromatin generated a strong DNase I-hypersensitive site, which was extended upstream upon binding of AML1 to 
A

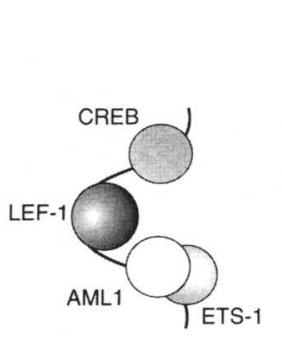

B

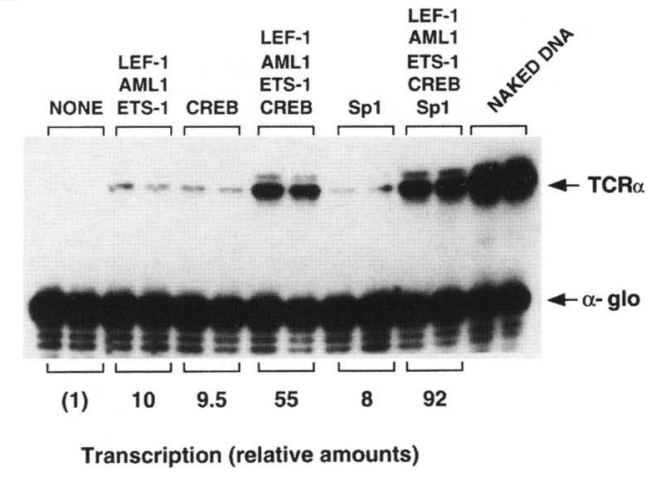

C

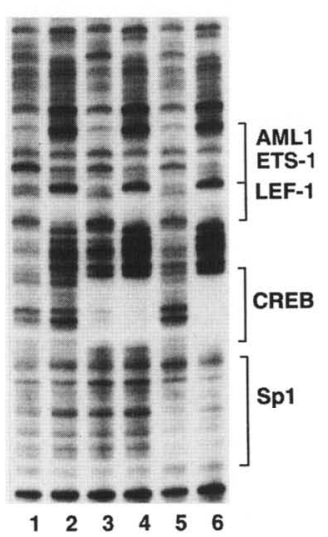

Figure 4. Synergistic activation of the TCR $\alpha$ enhancer by phosphorylated CREB and T-cell transcription factors on chromatin templates in vitro. $(A)$ Factor binding sites within the minimal TCR $\alpha$ enhancer. Bending of DNA by the LEF-1 HMG domain has been proposed to nucleate the assembly of a stereospecific enhancer complex (Grosschedl et al. 1994). (B) Analysis of the ability of P-CREB and the T-cell transcription factors (LEF-1, AML1, and Ets-1) to activate the TCR $\alpha$ enhancer on chromatin templates in vitro. In this experiment, suboptimal concentrations of the individual transcription factors were used to test their ability to activate transcription synergistically. The individual purified transcription factors that were incubated with the TCR $\alpha$ enhancer during nucleosome assembly are indicated above each lane. Proteins were used at the following concentrations: LEF-1 (100 nM), AML1 ( $\alpha$ subunit, $10 \mathrm{nM} ; \beta$ subunit, $50 \mathrm{nM})$, Ets-1 (110 nM), P-CREB (50 nM), and Sp1 (20 nM). Arrows indicate the positions of the TCR $\alpha$ enhancer-dependent transcript and $\alpha$-globin (control) RNAs. Naked DNA templates were not subjected to chromatin assembly. RNAs were detected by primer extension, and the numbers below each lane indicate the relative amounts of RNA in each lane as determined by PhosphorImager scanning. Transcription was carried out using HeLa nuclear extracts. $(C)$ DNase I footprint analysis of the binding of transcription factors to the chromatin templates derived from the reactions shown in Figure $1 \mathrm{~B}$. Aliquots of the chromatin templates were removed prior to the addition of the Hela nuclear transcription extract, digested with DNase I, and analyzed by primer extension. The location of specific transcription factor binding sites is indicated with brackets alongside the panel. (Lane 1) No added protein; (lane 2) T-cell factors (LEF-1, AML1, Ets-1); (lane 3) P-CREB; (lane 4) P-CREB and the T-cell factors; (lane 5) Sp1; (lane 6) Sp1, P-CREB, and the T-cell factors.

the distal region of the enhancer (Fig. 5B). As mentioned above, treatment of CREB with PKA did not affect its ability to bind to the chromatin templates in DNase I footprint experiments. Similarly, phosphorylation of CREB did not influence the formation of DNase I hypersensitive sites in the enhancer, nor did it affect the ability of CREB to disrupt the nucleosomal array in the vicinity of the enhancer, as assessed by micrococcal nuclease digestion of the chromatin templates hybridized with an enhancer-specific probe (data not shown). Thus, activation of the TCR $\alpha$ enhancer in vitro was accompanied by striking changes in the local chromatin structure that were induced upon binding CREB and the other enhancer-binding factors, and these alterations of chromatin structure occured independently of transcription or changes in the phosphorylation state of the CREB transactivation domain.

\section{The LEF-1 HMG domain facilitates binding of AML1/Ets-1 to the TCR $\alpha$ enhancer on chromatin}

We next tested the ability of CREB and the T-cell proteins to bind to the enhancer and activate transcription when added in different combinations to the chromatin templates. In the experiment shown in Figure 6A, the T-cell transcription complex was assembled onto the enhancer in the presence of P-CREB. Under these conditions, each factor contributed incrementally to TCR $\alpha$ enhancer activation. Analysis of the binding of the various factors to the chromatin templates in this experiment revealed that Ets-1 strengthens the binding of AML1 (Fig. 6B, cf. lanes 4 and 5), consistent with a previous study showing that AMLl and Ets-1 bind in a highly cooperative manner to the TCR $\alpha$ enhancer on nonchromatin DNA (Giese et al. 1995). Unexpectedly, however, we found that the binding of the AML1/Ets-1 complex was further strengthened upon the addition of LEF-1 to the reaction (Fig. 6B, cf. lanes 5 and 6), and there was a concomitant enhancement of the nuclease-hypersensitive sites in the distal region of the AML1/Ets-1 composite binding element. This result was surprising because LEF-1 does not enhance the binding of the AML1/Ets-1 complex in DNase I footprint experiments carried out with naked DNA templates (data not shown; similar findings were also reported by Giese et al. 1995). We reported previously that the binding of T-cell factors in Jurkat T-cell nuclear extracts to the AML1/Ets-1 core element is not affected by mutations that eliminate binding of LEF-1, further suggesting that LEF-1 does not facilitate binding of the AML1/Ets-1 complex on naked DNA even in the presence of other T-cell nuclear factors (Waterman and Jones 1990).

Binding of LEF-1 is accompanied by a striking bend in the DNA helix, which is mediated through the HMG domain (Giese et al. 1992). To determine whether the LEF-1 HMG domain is sufficient to recruit the AML1/ 
A

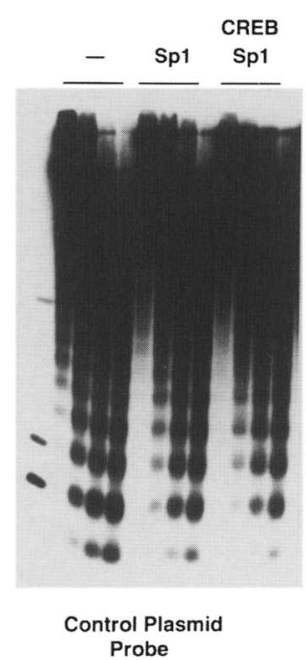

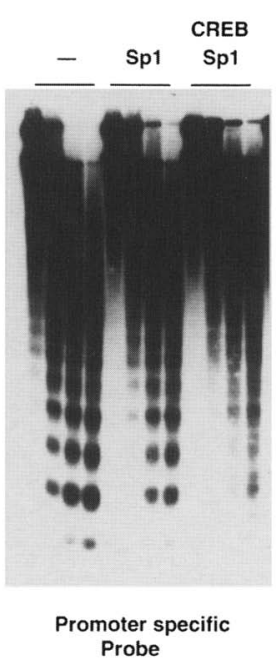

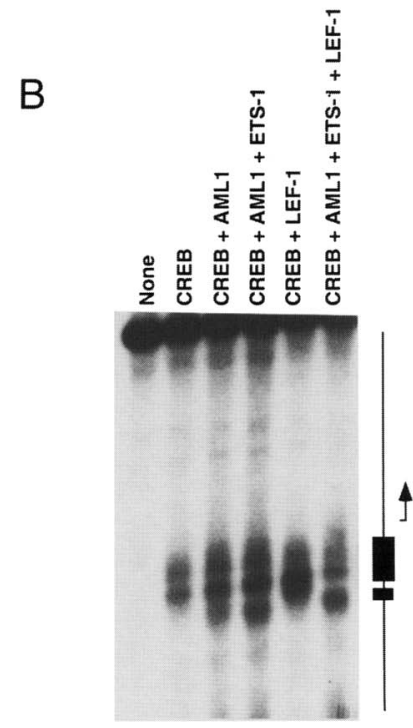

DNase I Hypersensitivity

Figure 5. Binding of CREB and the T-cell factor complex to the TCR $\alpha$ enhancer disrupts the local chromatin structure and induces the formation of DNase I-hypersensitive sites. (A) Chromatin templates were analyzed by micrococcal nuclease digestion $\left(3,8,16\right.$, and $25 \mathrm{~min}$ at $30^{\circ} \mathrm{C}$, as indicated above each lane) followed by agarose gel electrophoresis of the nucleosomal array and Southern transfer to nitrocellulose filters. The filters were sequentially hybridized to a control plasmid DNA probe (located $1000 \mathrm{bp}$ upstream of the TCR $\alpha$ enhancer), to assess

the bulk chromatin structure, and to a probe overlapping the TATA box in the pTCR $\alpha$ promoter. Purified proteins that were bound to the TCR $\alpha$ enhancer during nucleosome assembly are indicated above each lane. $(B)$ Binding of P-CREB and the T-cell enhancer factors induces DNase I hypersensitive sites within the TCR $\alpha$ enhancer. Aliquots of the chromatin templates that were used for the transcription reactions shown in Figure 6C were digested with DNase I, cleaved with NdeI (-1062 on the plasmid vector), resolved by agarose gel electrophoresis, and transferred to a nitrocellulose filter. The panels were hybridized to a labeled primer located at position -1000 as described in Materials and Methods. The relative locations of the TCR $\alpha$ enhancer (box) and the transcription start site (arrow) are indicated to the right.

Ets-1 protein complex to the TCR $\alpha$ enhancer, the enhancer-binding proteins were assembled stepwise on the TCR $\alpha$ enhancer chromatin templates in the presence of P-CREB. Each of the enhancer-binding proteins was found to augment transcription under these conditions. Analysis of these same templates in DNase I footprint experiments demonstrated that Ets-1 could stabilize the binding of AMLl, although the binding of this protein complex remained relatively weak. Again, addition of LEF-1 dramatically enhanced binding of AML1/Ets-1 to the enhancer (Fig. 6D). Interestingly, a truncation mutant of LEF-1 that contains only the 88-amino-acid HMG DNA-binding domain was also able to facilitate the binding of AML1/Ets-1 to the enhancer (Fig. 6D, cf. lanes 6 and 8). In vitro transcription experiments with these templates indicate that the LEF-1 HMG 88 domain could activate transcription from TCR $\alpha$ enhancer under these conditions, although its activity remained less than that observed with the full-length LEF-1 protein (Fig. 6C). The activity of LEF-1 was not optimal in this experiment, and thus it is possible that the difference in activity between full-length LEF-1 and the HMG domain may be even greater than that observed in Figure $6 \mathrm{C}$. We conclude that the LEF-1 HMG domain facilitates the assembly of AML1/Ets-1 into a higher-order complex on the TCR $\alpha$ enhancer, potentially mediated through the ability of the HMG box to bend the DNA. However, optimal LEF-1 activity in this system requires the transactivation domain located amino-terminal to the HMG domain, which functions independently of the assembly of this higher-order protein complex on the TCR $\alpha$ enhancer.
LEF-1 promotes binding of AML1/Ets-1 to the TCR $\alpha$ enhancer independently of CREB

The data presented above indicate that LEF-1 can enhance assembly and activation of the TCR $\alpha$ enhancer, in part through its ability to stimulate the binding of AML1 and Ets-1 to the chromatin templates. As described in the introduction, it has been proposed that the CREbinding proteins also play a critical role in the assembly of the TCR $\alpha$ enhancer complex through their ability to interact with Ets-1 on LEF-1-bound DNA. To test this possibility directly, we examined whether CREB was necessary for the cooperative assembly of the higher-order T-cell transcription factor complex on chromatin. In this experiment, the T-cell factors were assembled on the enhancer in the absence or presence of CREB. As we reported previously, LEF-1 was not able to activate the enhancer when incubated with chromatin templates on its own (Fig. 7A). By contrast, the AML1/Ets-1 protein complex, which binds DNA more weakly than LEF-1, was able to stimulate transcription from the TCR $\alpha$ enhancer. Addition of LEF-1 augmented transcriptional activity of AML1/Ets-1 (Fig. 7A) and greatly stabilized its binding to the enhancer in the absence of P-CREB (Fig. 7B, cf. lanes 3 and 4). P-CREB activated transcription synergistically with the T-cell factors (Fig. 7A), but it did not further affect their ability to bind to the enhancer (Fig. 7B, cf. lanes 4 and 5). However, in several experiments the binding of P-CREB was noticeably enhanced by the T-cell factors (Figs. 6 and 7), and this stabilization of CREB binding might help contribute to transcriptional synergy. We conclude from these studies that the 
Mayall et al.

Figure 6. LEF-1 strongly enhances binding of AML1/Ets-1 to the TCR $\alpha$ enhancer on chromatin templates. (A) Transcriptional activation of the TCR $\alpha$ enhancer by P-CREB, alone and in combination with the T-cell enhancer-binding proteins. In this experiment, suboptimal recombinant CREB (20 nM) was phosphorylated with protein kinase A prior to its addition to the chromatin assembly reactions. RNA transcripts were detected by primer extension and quantified as described in Materials and Methods. (B) DNase I footprint analysis of aliquots of the same chromatin templates that were analyzed for transcription in $A$. (Lane 1) No added enhancer-binding proteins; (lane 2) CREB alone; (lane 3) P. CREB and LEF-1; (lane 4) P-CREB and AML1; (lane 5) P-CREB, AML1, and Ets-1; (lane 6) P-CREB, LEF-1, AML1, and Ets-1. Brackets to the right of the panel indicate the DNA-binding sites on the enhancer. (C) Comparison of the relative abilities of LEF-1 and a mutant LEF-1 protein containing the HMG DNA-binding domain (HMG88, amino acids 297-384; Sheridan et al. 1995) to activate the TCR $\alpha$ enhancer. RNA transcripts were detected by primer extension, and the relative transcriptional activity was determined by PhosphorImager scanning of the gel. Equivalent DNAbinding units of LEF-1 and the HMG88 protein were used in this experiment, as assessed by gel mobility shift assays using oligodeoxynucleotides containing the LEF-1 binding site from the TCR $\alpha$ enhancer. $(D)$ DNase I footprint analysis of the reactions shown in $C$. (Lane 1) No added enhancer-binding proteins; (lane 2) P-CREB alone; (lane 3) P-CREB and AML1; (lane 4) P-CREB, AML1, and Ets-1; (lane 5) P-CREB and LEF-1; (lane 6) P-CREB, LEF-1, AML1, and Ets-1; (lane 7) P-CREB and HMG 88; (lane 8) P-CREB, HMG 88, AML1, and Ets-1. Proteins bound to the chromatin templates were analyzed in the absence of HeLa transcription extract, as described in Materials and Methods. Brackets to the right indicate the DNA-binding sites on the enhancer.

T-cell proteins assemble as a complex onto the TCR $\alpha$ enhancer independently of P-CREB, and subsequently act synergistically with P-CREB to stimulate transcription from nucleosomal DNA.

\section{Discussion}

In this study we have examined the ability of CREB and three different $T$ cell-enriched transcription factors to assemble on the TCR $\alpha$ enhancer and activate transcription in vitro in the context of a chromatin template. Our results indicate that the specific arrangment of transcription factor binding sites within the TCR $\alpha$ enhancer core directs the cooperative stepwise assembly of the lymphoid-enriched transcription factors LEF-1, AML1, and Ets-1. At least three separate interactions are required to generate this T-cell factor complex: (1) formation of the AML1 (PEBP2/CBF) heterodimer, which occurs in solu- tion and strongly enhances the association of the $\alpha$ subunit of AML1 with DNA (Kagoshima et al. 1993); (2) recruitment of Ets-1 by AML1 to a composite element in the TCR $\alpha$ enhancer core through cooperative DNAbinding interactions (Wotton et al. 1994; Giese et al. 1995); and (3) enhanced binding of the AML1/Ets-1 ternary complex by the LEF-1 HMG protein (illustrated in Figs. 6 and 7), which to date we have detected only with chromatin templates. These results suggest that LEF-1 can act as a cell type-specific docking protein to facilitate the binding of other cell type-restricted proteins to the composite core element of the TCR $\alpha$ enhancer. At saturating protein concentrations, this complex of lymphoidspecific proteins is sufficient to activate the TCR $\alpha$ enhancer in vitro. When the enhancer-binding factors are limiting, however, they are found to activate transcription in a highly synergistic manner with protein kinase A-phosphorylated CREB, which binds independently of 
A

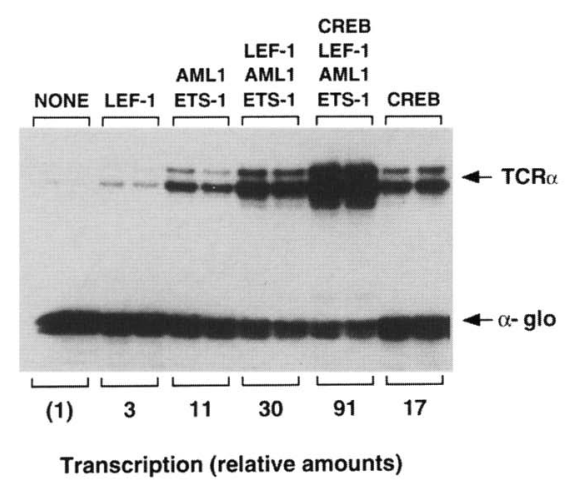

B

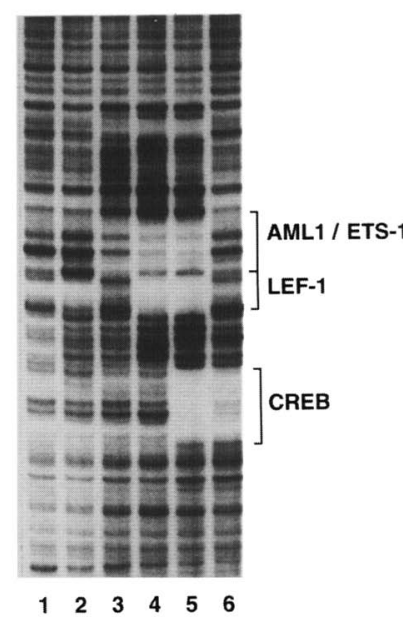

Figure 7. LEF-1 facilitates binding of AML1/Ets-1 to the TCR $\alpha$ enhancer independently of CREB. $(A)$ In vitro transcription reactions carried out using pTCR $\alpha$ chromatin templates that were assembled in the presence of different combinations of LEF-1 (100 $\mathrm{nM}$ ), AML1 ( $\alpha$ subunit $10 \mathrm{nM} ; \beta$ subunit 50 $\mathrm{nM})$, Ets-1 (110 nM), and P-CREB (70 nM), as indicated above each lane. (B) DNase I footprint analysis of the same chromatin templates that were analyzed in $A$ for transcriptional activity in vitro. Enhancer-binding proteins present in each reaction are indicated above each lane. Proteins bound to the chromatin templates were analyzed in the absence of HeLa transcription extract, as described in Materials and Methods. the T-cell transcription factor complex to a neighboring site on the TCR $\alpha$ enhancer. In this way, the TCR $\alpha$ enhancer is structured to respond optimally in cellular environments that contain activated (i.e., Ser133-phosphorylated) CREB as well as the appropriate combination of lymphoid cell-enriched regulatory proteins.

\section{PKA-phosphorylation of CREB enhances its transcriptional activity on chromatin templates}

Based in part on the observation that recombinant Ets-1 can interact in vitro with a monomeric isoform of ATF2 (ATF2 ${ }_{194}$ ), but not with CREB or the full-length (dimeric) ATF2, Giese et al. (1995) recently have proposed a model for TCR $\alpha$ enhancer assembly in which distortion of the DNA helix by LEF-1 is necessary to facilitate direct protein-protein interactions between Ets-1 and ATF-related proteins bound to the CRE. By contrast, the results presented here suggest that the action of the TCR $\alpha$ CRE is not restricted to distinctive members of the ATF protein family. Specifically, two lines of evidence indicate that CREB is a bona fide activator of the TCR $\alpha$ enhancer in Jurkat T cells: First, expression of protein kinase A activates the enhancer through the CRE in vivo; second, GAL4/CREB is shown to activate a GAL4-substituted $\mathrm{TCR} \alpha$ enhancer and confer PKA-responsiveness to the enhancer in T-cell lines. Our data further show that recombinant CREB activates the TCR $\alpha$ enhancer on nucleosome-assembled DNA in vitro, and that phosphorylation of CREB by PKA markedly improves its transcriptional activity on chromatin. Importantly, phosphorylated CREB was also capable of activating transcription synergistically with the lymphoid-specific proteins (LEF-1, AML1, and Ets-1) assembled at the enhancer core. A point mutation affecting the CREB phosphorylation site abrogated responsiveness to PKA, and phosphorylation was found to affect the transcriptional activity of CREB but not its ability to bind to the nucleosomal DNA templates. Although we have not directly compared the activity of CREB and ATF $2_{194}$ in vitro, we can nevertheless conclude that CREB is a relevant acti- vator of the TCR $\alpha$ enhancer in vivo and in vitro, and that specific isoforms of the different CRE-binding proteins that can be shown to bind directly to Ets-1 are not critical for enhancer activity. The recent report that transgenic mice expressing a dominant-negative form of CREB in thymocytes support normal T-cell development (Barton et al. 1996) indicates that CRE-binding proteins other than CREB are also likely to be capable of regulating $\mathrm{T}$-cell receptor gene expression in vivo.

There are striking parallels between the action of the minimal TCR $\alpha$ enhancer and growth factor-stimulated regulation of the c-fos promoter, which is mediated through the cooperative action of CREB and the factors bound to the composite serum-response element, namely the serum-response factor (SRF) and the Ets-related protein Elk-1 (Ginty et al. 1994; Xing et al. 1996). Growth factor stimulation of the Ras-dependent kinase cascade results in the activation of MAPK and pp90RSK proteins, which phosphorylate different transcription factors critical for activation of the c-fos promoter. Phosphorylation of the Elk-1 transcription activation domain by MAPK stabilizes its ability to form a ternary complex with SRF on the c-fos serum-response element (Gille et al. 1992; Marais et al. 1993). Activated pp90RSK and related kinases have been shown to phosphorylate CREB (at Ser133), which strongly enhances its ability to activate transcription synergistically with the factors bound to the c-fos serum response element (SRE) in growth factor-treated cells (Ginty et al. 1994; Xing et al. 1996). The pp90RSK protein also forms a stable complex with the CREB-binding protein, CBP, and this complex appears to be important for c-fos promoter activity in growth factortreated cells (Nakajima et al. 1996). Interestingly, the growth factor-dependent CBP-pp90RSK complex does not support P-CREB activity on isolated CRE sites (Arias et al. 1994; Ginty et al. 1994; Brindle et al. 1995; Nakajima et al. 1996), and instead it actively interferes with the cyclic AMP-induced signaling pathway (Nakajima et al. 1996). Thus the context of the CRE within an enhancer determines whether CREB will mediate enhanced or reduced transcription in response to growth 
factor signaling. Because T-cell activation similarly leads to phosphorylation of CREB and the formation of the pp90RSK/CBP complex (Brindle et al. 1995; Nakajima et al. 1996), it is likely that these steps promote the synergistic activation of P-CREB and the T-cell factors at the TCR $\alpha$ enhancer core in vivo. These findings suggest that phosphorylation of CREB by either PKA or by RSK would activate the TCR $\alpha$ enhancer in a similar manner; however, further studies are needed to establish the role of RSK and the RSK-CBP complex in the regulation of TCR $\alpha$ enhancer activity in vivo. Thus we envision that the unique context provided by the TCR $\alpha$ enhancer, by analogy with the c-fos promoter, would enhance the concerted action of P-CREB with the various $\mathrm{T}$-cell enhancer-binding proteins and serve to redirect transcription from simple CRE-responsive promoters to the more complex $\mathrm{T}$ cell-specific enhancers.

Although the precise role of CBP as a coactivator of signal-responsive transcription factors is unclear, it is known to interact with general transcription factors and a multiprotein complex containing RNA polymerase II (Kwok et al. 1994; Brindle et al. 1995; Kee et al. 1996), and recently it also has been shown to function as a histone acetyltransferase in vitro (Bannister and Kouzarides 1996; Ogryzko et al. 1996). This latter finding raises the interesting possibility that CBP can affect the extent of nucleosome acetylation at targeted promoters, which in principle could enhance initiation as well as transcript elongation on chromatin. It is unlikely that the enhanced transcriptional activity of P-CREB on nucleosomal DNA templates that we report here is a result of CBP-mediated changes in histone acetylation, however, in part because our reactions did not contain exogenous acetyl coenzyme $\mathrm{A}(\mathrm{CoA})$, a necessary substrate for de novo histone acetylation. As CBP is tightly associated with RNA polymerase II (Pol II) multiprotein complexes in nuclear extracts (Brindle et al. 1995; Kee et al. 1996), it seems likely that the effect of P-CREB that we observe here is attributable instead to its ability to interact (indirectly) with the general RNA Pol II transcription machinery. Thus, under conditions where P-CREB is incubated with the DNA template during nucleosome assembly in the absence of CBP, we envision that the mechanism of regulation is similar to that which has been observed with naked DNA templates that have been transcribed in HeLa nuclear extracts treated with PKA (Brindle et al. 1995; Kee et al 1996). Our findings do not exclude an additional effect of CBP on nucleosome acetylation, however, which could increase the specific transcriptional activity of P-CREB on chromatin in vitro beyond that which we have observed here. The in vitro transcription system used here should be useful in the future in establishing the extent to which histone acetylation by CBP might influence transcriptional activation by phosphorylated CREB.

The LEF-1 HMG domain facilitates binding of the AML1/Ets-1 complex on chromatin

As we observed previously with the HIV-1 enhancer (Sheridan et al. 1995), the LEF-1 HMG protein was inca- pable of activating transcription when incubated on its own with chromatin templates. However, LEF-1 strongly enhanced transcription when it was added together with AML1 and Ets-1 to the TCR $\alpha$ enhancer, and concomitant with transcriptional activation, it was found to stabilize the binding of the AML1/Ets-1 complex to nucleosomal DNA. Interestingly, the LEF-1 HMG domain was sufficient not only to facilitate the assembly of a higher-order complex with AML1 and Ets-1 on the enhancer but also to activate transcription, albeit modestly, from the nucleosome-assembled TCR $\alpha$ enhancer (Fig. 7). The ability of the LEF-1 HMG domain to activate the TCR $\alpha$ enhancer is consistent with previous results obtained by overexpressing the T-cell enriched factors in B-cell lines in transient expression assays (Giese et al. 1995). Importantly, however, optimal LEF-1 transcriptional activity (in vivo and in vitro) requires an intact transcriptional activation domain .Because the LEF-1 trans-activation domain is functional in this in vitro system, it must interact with either Ets-1 and AML1 or with general transcription factors or coactivators that are not restricted to lymphoid cells.

It is interesting that the higher-order nucleoprotein complex assembled by LEF-1 was preferentially detected on nucleosome-assembled DNA. Chromatin assembly has been shown to enhance cooperativity in general among DNA-bound proteins (Adams and Workman 1995), although under the conditions used here, that is, where the factors are bound with the DNA template during nucleosome assembly, the enhanced cooperativity is specific for the T-cell proteins that bind to the composite core element abutting the LEF-1 binding site. Similarly, we have shown previously that cooperative binding of $\mathrm{Sp} 1$ and NF- $\mathrm{kB}$ to the HIV-1 promoter (which can be detected on naked DNA) is preferentially enhanced on chromatin templates (Pazin et al. 1996). Thus, proteinprotein interactions among specific regulatory proteins may also be facilitated on chromatin templates; for example, nucleosome assembly may alter the spatial configuration of the AML/Ets-1 composite element on the TCR $\alpha$ enhancer such that the proteins are optimally positioned to be stabilized by LEF-1-induced DNA bending.

In contrast to these results obtained here with the TCR $\alpha$ enhancer, we have demonstrated previously that the HMG domain of LEF-1 cannot activate transcription from the HIV-1 enhancer in vivo (Sheridan et al. 1995). The HIV-1 enhancer is arranged similarly to the TCR $\alpha$ enhancer in that the LEF-1 binding site is flanked on one side by a composite element for Ets- 1 and another factor (in this case, USF) and on the other side by a binding site for NF- $\mathrm{kB}$, which is positioned at a similar distance from LEF- 1 as is the CRE motif on the TCR $\alpha$ enhancer. Binding of Ets-1 and USF/TFE-3 to the HIV-1 enhancer is highly cooperative on nonchromatin templates in vitro (M.L. Voz, P.L. Sheridan, and K.A. Jones, unpubl.), similar to the cooperative interactions observed between Ets-1 and AML1 on the TCR $\alpha$ enhancer. Studies are under way to assess the ability of LEF-1 to facilitate the binding of Ets-1 and USF/TFE-3 to the HIV-1 enhancer on chromatin templates. From the comparison of these 
two enhancers, we speculate that the precise architecture and relative affinity of individual transcription factor binding sites in LEF-1-responsive enhancers plays a key role in specifying the extent to which an enhancer relies upon LEF-1-induced bending of the DNA to assemble higher-order protein complexes.

The results presented here suggest a new model for TCR $\alpha$ enhancer activation, a key feature of which is the LEF-1-promoted assembly of a T-cell transcription factor complex that binds to the enhancer independently of CREB. The interdependence of the T-cell factor transcription complex suggests that these proteins combine to present a unified surface for the recruitment of specific transcriptional coactivators or the general RNA Pol II transcription machinery. In activated $T$ cells, the assembled T-cell factor complex is positioned to respond rapidly to levels activated (i.e., Ser-133-phosphorylated) CREB. Further experiments with this biochemical system should help elaborate the role of CBP and downstream transcriptional activators in the regulation of the $\mathrm{TCR} \alpha$ enhancer in a chromatin environment.

\section{Materials and methods}

\section{Transient expression assays}

Transient transfections were performed by electroporation of TPA-stimulated Jurkat cells (activated by treatment with 50 $\mathrm{ng} / \mathrm{ml}$ of TPA for $15 \mathrm{hr}$ at $37^{\circ} \mathrm{Cl}$ with $2 \mu \mathrm{g}$ of reporter gene TCR $\alpha 1$ tk or TCR $\alpha 2$ tk DNA (Carlsson et al. 1993), 1 pg of pCMV/CAT, and $10 \mu \mathrm{g}$ of pMT/PKA (Mellon et al. 1989), pCMV/Tax (Cann et al. 1989), GAL4/CREB (Brindle et al. 1993), pRSV/CBP (Kwok et al. 1994), or carrier DNA, as indicated in the accompanying figure legends. Luciferase and CAT activities were assayed as described previously (Carlsson et al. 1993) and luciferase activity was corrected to the internal control pCMV/CAT to standardize for transfection efficiency.

\section{Expression of recombinant TCR $\alpha$ enhancer-binding proteins}

Recombinant Ets-1, LEF-1, and the truncated (HMG 88) LEF-1 HMG domain proteins were expressed in bacteria as fusion proteins with gene-10, and purified by chromatography on heparinagarose and MonoS resins, as described previously (Sheridan et al. 1995). The full-length human AML1B protein was expressed in bacteria as a (His) ${ }_{6}$ fusion protein (pET28AML1B). This expression plasmid was generated by inserting the EcoRI fragment from pCMV5AML1B (Meyers et al. 1995) into the EcoRI site of pET28a(+) (Novagen). Bacterial cells (BL21) containing the expressed His-tagged AML1B were resuspended in lysis buffer $(20$ mM HEPES at $\mathrm{pH} 8,200 \mathrm{mM} \mathrm{KCl}, 5 \mathrm{mM} \mathrm{MgCl}_{2}, 0.1 \mathrm{~mm}$ PMSF, and $2 \mathrm{mg} / \mathrm{ml}$ of benzamidine) and disrupted by sonication. The supernatant fraction was spun at $100,000 \mathrm{~g}$ for $30 \mathrm{~min}$, and the pellet was resuspended in lysis buffer containing $8 \mathrm{M}$ urea. After repeated centrifugation at $100,000 \mathrm{~g}$ for $30 \mathrm{~min}$, the supernatant was incubated with Ni-NTA agarose resin for $1 \mathrm{hr}$ and eluted with imidazole $(300 \mathrm{~mm})$. Peak fractions containing AML1B were pooled and dialyzed stepwise against $25 \mathrm{mM}$ HEPES at $\mathrm{pH}$ $8,12.5 \mathrm{~mm} \mathrm{MgCl}_{2}, 2 \mathrm{~mm}$ DTT, $0.1 \mathrm{mM}$ PMSF, $10 \%$ glycerol, 0.2 $\mathrm{M} \mathrm{KCl}$, and $0.5 \mathrm{M}$ urea prior to freezing. The non-DNA-binding ( $\beta$ ) subunit of AML1 was expressed as the full-length mouse PEBP2 $\beta 2$ protein, and was purified as described previously (Ogawa et al. 1993a). The purified AML1B bound specifically to the TCR $\alpha$ enhancer DNA in gel mobility shift assays, and its relative binding affinity increased 10 -fold upon complexing with the PEBP2 $\beta 2$ subunit (data not shown). CREB and mutant CREBM1 were expressed as nonfusion proteins in bacteria and purified as described previously (Gonzales et al. 1991). All purified protein preparations $(0.3-1 \mathrm{mg} / \mathrm{ml})$ were stored at $-100^{\circ} \mathrm{C}$ and diluted before use to the final concentration indicated in each figure legend.

Where indicated, CREB was phosphorylated with protein kinase A prior to its addition to the nucleosome assembly reaction. Reactions containing $5 \mu \mathrm{g}$ of purified recombinant CREB were incubated with $10 \mathrm{nM}$ purified protein kinase $\mathrm{A}$ in the presence of $5 \mathrm{~mm} \mathrm{ATP}$ and $100 \mathrm{~mm}$ DTT for $30 \mathrm{~min}$ at $30^{\circ} \mathrm{C}$. Protein kinase A was then inactivated by incubation with $5 \mu \mathrm{M}$ PKi (Sigma) for $30 \mathrm{~min}$ at $30^{\circ} \mathrm{C}$ prior to its addition to the chromatin assembly reactions. Reactions containing unphosphorylated CREB were incubated in parallel with only ATP and DTT followed by addition of PKi after incubation.

\section{Chromatin assembly and in vitro transcription reactions}

Chromatin was assembled with Drosophila S-190 extract, core histones, histone $\mathrm{H1}$, and an ATP regenerating system, prepared and analyzed as described previously (Bulger and Kadonaga 1994; Sheridan et al. 1995). Proteins were bound to the DNA for $20 \mathrm{~min}$ on ice prior to the addition of the S-190 assembly extract and purified histone components. Nuclear transcription extracts were prepared from the HeLa-S3 cell line as described by Waterman and Jones (1990). To monitor TCR $\alpha$ enhancer activity in vitro, one copy of the minimal $(115 \mathrm{bp})$ core region of the human TCR $\alpha$ enhancer, which is necessary and sufficient for $\mathrm{T}$-cell specific enhancer activity in TCR $\alpha / \beta+\mathrm{T}$-cell lines, was subcloned as a BamHI-BgIII fragment (pTCR $\alpha$ ) upstream of the minimal HIV-1 promoter and the luciferase gene at a BamHI site (position -85) in pHIV-1/LUC (Carlsson et al. 1993). Nucleosome assembly reactions were incubated for $5 \mathrm{hr}$ at $30^{\circ} \mathrm{C}$, and duplicate aliquots of each chromatin template were analyzed by in vitro transcription. As an internal control for RNA recovery, $50 \mathrm{ng}$ of $\alpha$-globin $(\alpha$-glo) DNA template was added to the transcription after nucleosome assembly. Transcription reactions were analyzed by primer extension as described previously (Sheridan et al. 1995). Briefly, $100 \mathrm{ng}$ of pTCR $\alpha$ chromatin template (or naked pTCR $\alpha$ DNA) was incubated with $50 \mathrm{ng}$ of $\alpha$-globin DNA in a $100 \mu \mathrm{l}$ reaction containing $20 \mathrm{~mm}$ HEPES at pH $8,7 \mathrm{mM} \mathrm{MgCl}_{2}, 30-70 \mathrm{~mm} \mathrm{KCl}, 300 \mathrm{ng}$ poly[d(I-C)], 2.5\% polyvinyl alcohol, and 80-100 $\mu \mathrm{g}$ of HeLa nuclear extract. After formation of preinititation complexes, rNTPs were added and transcription allowed to occur for $30 \mathrm{~min}$ at $30^{\circ} \mathrm{C}$. A primer that anneals at +56 to +80 relative to the RNA start site on pTCR $\alpha$ (5'-GCTTTATTGAGGCTTAAGCAGTGGG-3') was used for primer extension of in vitro synthesized RNA as well as for DNase I footprint and chromatin structure studies (see below). Quantitation of the resulting RNAs was carried out using a PhosphorImager (Molecular Dynamics).

To carry out these experiments, we had anticipated that it might be necessary to first deplete the endogeneous CRE-binding proteins from the HeLa nuclear extract. Under the conditions used in these experiments, however, the endogeneous CREB present in the Hela extract was not capable of binding or activating transcription from the nucleosomal DNA templates. This is supported by the observation that the pTCR $\alpha$ enhancer templates were fully repressed when analyzed in the absence of added enhancer-binding proteins (Fig. 1B) and the fact that mutations in the CRE abolished CREB activity yet had no effect on transcriptional activation by the T-cell factors. Thus the levels of CREB (or chromatin remodeling activities) present in the HeLa extract appear to be insufficient to permit the protein to 
gain access to the chromatin template under the conditions used here.

\section{Analysis of nucleosomal DNA templates by DNase I footprint and chromatin structure assays.}

For many of the experiments shown here, the same chromatin templates that were used for the in vitro transcription reactions were also analyzed for binding of individual transcription factors by primer-extension DNase I footprint experiments, and for any effects of the factors on the underlying chromatin structure. For DNase I footprint experiments, chromatin templates 1750 $\mathrm{ng}$ / were incubated with $3.75 \mu \mathrm{g}$ of DNase I in the absence of HeLa transcription extract for $10 \mathrm{~min}$ at room temperature as described by Pazin et al. (1996). The digested DNA fragments were isolated and analyzed by primer extension with Vent ( $\left.\mathrm{exo}^{-}\right)$ polymerase (New England Biolabs) and the TCR $\alpha$ enhancer ${ }^{32} \mathrm{P}$ labeled primer $1+56$ to +80 relative to the RNA start site; for sequence, see above). The DNase I footprint reactions were then analyzed by electrophoresis on $6 \%$ buffer gradient gels $10.5 \times$ TBE to $0.6 \times \mathrm{TBE}$ and $1 \mathrm{M}$ sodium acetate) and autoradiography.

The chromatin structure of the nucleosomal templates was also assessed for some of the in vitro transcription reactions. Aliquots of the same DNase I-treated samples that were analyzed by primer extension footprint reactions were also analyzed for DNase-hypersensitive site formation by digestion with NdeI restriction enzyme. The restriction digests were transferred to nitrocellulose filters (Southern blots), and hybridized to an NdeI primer $15^{\prime}$-GCACTCTCAGTACAATCTGCTCTGATGCCGC-3'). For micrococcal nuclease ladder disruption analysis, unpurified chromatin $(5 \mu \mathrm{g})$ was partially digested with micrococcal nuclease at $30^{\circ} \mathrm{C}$ for $3,8,16$, and $25 \mathrm{~min}$ in the absence of HeLa transcription extract. Aliquots of these micrococcal digests were analyzed by agarose gel electrophoresis, transferred to nitrocellulose, and sequentially probed with $\mathrm{NdeI}$ and TCR $\alpha$ primers. The NdeI primer (which anneals 1000 bp upstream of the TCR $\alpha$ enhancer in $\mathrm{PTCR} \alpha$ ) was used to analyze the chromatin structure in the distal regions beyond the enhancer, whereas the TCR $\alpha$ primer was used to analyze the effects of enhancer-binding proteins on the nucleosome array in the vicinity of the TCR $\alpha$ enhancer.

\section{Acknowledgments}

We thank Amy Andrews for excellent technical assistance on this project. We are also grateful to Susan $M$. Taylor (University of California at San Diego) for supplying purified protein kinase A, Scott W. Hiebert (St. Jude Children's Research Hospital) for the human AML1B clone, Yoshiaki Ito (Kyoto University) for the PEBP2 $\beta$ clone, and Beverly M. Emerson (The Salk Institute) for helpful comments on the manuscript. This work was supported by a program project grant from the National Institutes of Health to K.A.J. and M.R.M. (CA54418) and by The G. Harold and Leila Y. Mathers Foundation.

The publication costs of this article were defrayed in part by payment of page charges. This article must therefore be hereby marked "advertisement" in accordance with 18 USC section 1734 solely to indicate this fact.

\section{References}

Adams, C.C. and J.L. Workman. 1995. Binding of disparate transcriptional activators to nucleosomal DNA is inherently cooperative. Mol. Cell. Biol. 15: 1405-1421.

Arany, Z., W.R. Sellers, D.M. Livingston, and R. Eckner. 1994.
E1A-associated p300 and CREB-associated CBP belong to a conserved family of coactivators. Cell 77: 799-800.

Arias, J., A. Alberts, P. Brindle, F. Claret, T. Smeal, M. Karin, J. Feramisco, and M. Montminy. 1994. Activation of cAMP and mitogen responsive genes relies on a common nuclear factor. Nature 370: 226-228.

Bae, S.-C., E. Ogawa, M. Maruyama, H. Oka, M. Satake, K. Shigesada, N. Jenkins, D. Gilbert, N. Copeland, and Y. Ito. 1994. PEBP2 $\alpha$ B/mouse AML1 consists of multiple isoforms that possses differential transactivation potentials. Mol. Cell. Biol. 14: 3242-3252.

Bannister, A.J. and T. Kouzarides. 1996. The CBP co-activator is a histone acetyltransferase. Nature 384: 641-643.

Barton, K., N. Muthuswamy, M. Chanyangam, C. Fischer, C. Clendenin, and J.M. Leiden. 1996. Defective thymocyte proliferation and IL-2 production in transgenic mice expressing a dominant-negative form of CREB. Nature 379: 81-85.

Brindle, P., S. Linke, and M.R. Montminy. 1993. Protein-kinaseA-dependent activator in transcription factor CREB reveals new role for CREM repressors. Nature 364: 821-824.

Brindle, P., T. Nakajima, and M.R. Montminy. 1995. Multiple protein kinase A-regulated events are required for transcriptional induction by cAMP. Proc. Natl. Acad. Sci. 92: 10521-10525.

Bulger, M. and J.T. Kadonaga. 1994. Biochemical reconstitution of chromatin with physiological nucleosome spacing. Methods Mol. Genet. 5: 241-262.

Cann, A.J., J.D. Rosenblatt, W. Wachsman, and I.S.Y. Chen. 1989. In vitro mutagenesis of the human T-cell leukemia virus types I and II tax genes. J. Virol. 63: 1474-1479.

Carlsson, P., M.L. Waterman, and K.A. Jones. 1993. The hLEF/ TCF- $1 \alpha$ HMG protein contains a context-dependent activation domain that induces the TCR $\alpha$ enhancer in $\mathrm{T}$ cells. Genes \& Dev. 7: 2418-2430.

Chakravarti, D., V.J. LaMorte, M.C. Nelson, T. Nakajima, I.G. Schulman, H. Jugilon, M. Montminy, and R.M. Evans. 1996. Role of CBP/P300 in nuclear receptor signalling. Nature 383: 99-103.

Chrivia, J.C., R.P. Kwok, N. Lamb, M. Hagiwara, M.R. Montminy, and R.H. Goodman. 1993. Phosphorylated CREB binds specifically to the nuclear protein CBP. Nature 365: 855-859.

Giese, K. and R. Grosschedl. 1993. LEF-1 contains an activation domain that stimulates transcription only in a specific context of factor-binding sites. EMBO I. 12: 4667-4676.

Giese, K., J. Cox, and R. Grosschedl. 1992. The HMG domain of lymphoid enhancer factor 1 bends DNA and facilitates assembly of functional nucleoprotein structures. Cell 69: 185-196.

Giese, K., C. Kingsley, J.R. Kirshner, and R. Grosschedl. 1995. Assembly and function of a TCR $\alpha$ enhancer complex is dependent on LEF-1-induced DNA bending and multiple protein-protein interactions. Genes \& Dev. 9: 995-1008.

Gille, R., A.D. Sharrocks, and P.E. Shaw. 1992. Phosphorylation of transcription factor p62TCF by MAP kinase stimulates ternary complex formation at the c-fos promoter. Nature 358: $414-417$.

Ginty, D.D., A. Bonni, and M.E. Greenberg. 1994. Nerve growth factor activates a Ras-dependent protein kinase that stimulates c-fos transcription via phosphorylation of CREB. Cell 77: 713-725.

Gonzales, G.A. and M.R. Montminy. 1989. Cyclic AMP stimulates somatostatin gene transcription by phosphorylation of CREB at serine 133. Cell 59: 675-680.

Gonzales, G.A., P. Menzel, J. Leonard, W.H. Fischer, and M.R. Montminy. 1991. Characterization of motifs which are critical for activity of the cyclic AMP-responsive transcription factor CREB. Mol. Cell. Biol. 11: 1306-1312.

Grosschedl, R., K. Giese, and J. Pagel. 1994. HMG domain pro- 
teins: Architectural elements in the assembly of nucleoprotein structures. Trends Genet. 10: 94-100.

Hernandez-Munain, C. and M.S. Krangel. 1994. Regulation of the T-cell receptor $\delta$ enhancer by functional cooperation between $\mathrm{c}$ myb and core-binding factors. Mol. Cell. Biol. 14: 473-483.

Ho, I.-C. and J.M. Leiden. 1990. Sequence-specific binding of human Ets-1 to the $T$ cell receptor alpha gene enhancer. Science 250: 814-818.

Ho, I.-C., L.-H. Yang, G. Morle and J.M. Leiden. 1989. A T-cellspecific transcriptional enhancer element $3^{\prime}$ of $\mathrm{C} \alpha$ in the human T-cell receptor $\alpha$ locus. Proc. Natl. Acad. Sci. 86: 6714-6718.

Kagoshima, H., K. Shigesada, M. Satake, Y. Ito, H. Miyoshi, M. Ohki, M. Pepling, and P. Gergen. 1993. The Runt domain identifies a new family of heteromeric transcriptional regulators. Trends Genet. 9: 338-341.

Kamakaka, R.T., M. Bulger, and J.T. Kadonaga. 1993. Potentiation of RNA polymerase II transcription by Gal4-VP16 during but not after DNA replication and chromatin assembly. Genes \& Dev. 7: 1779-1795.

Kee, B., J. Arias, and M.R. Montminy. 1996. Adaptor mediated recruitment of RNA polymerase II to a signal dependent activator. I. Biol. Chem. 271: 2373-2375.

Kwok, R.P., J.R. Lundblad, J.C. Chrivia, I.P. Richards, H.P. Bachinger, R.G. Brennan, S.G. Roberts, M.R. Green, and R.H. Goodman. 1994. Nuclear protein CBP is a coactivator for the transcription factor CREB. Nature 370: 223-226.

Liu, P., S.A. Tarle, A. Hajra, D.F. Clazton, P. Marlton, M. Freedman, M.J. Siciliano, and F.S. Collins. 1993. Fusion between transcription factor $C B F \beta / P E B P 2 \beta$ and a myosin heavy chain in acute myeloid leukemia. Science 261: 1041-1044.

Marais, R., J. Wynne, and R. Treisman. 1993. The SRF accessory protein Elk-1 contains a growth factor-regulated transcriptional activation domain. Cell 73: 381-393.

Mellon, P.L., C.H. Clegg, L.A. Correll, and G.S. McKnight. 1989. Regulation of transcription by cyclic AMP-dependent protein kinase. Proc. Natl. Acad. Sci. 86: 4887-4892.

Meyers, S., N. Lenny, and S.W. Hiebert. 1995. The $\mathrm{t}(8 ; 21)$ fusion protein interferes with AML-1B-dependent transcriptional activation. Mol. Cell. Biol. 15: 1974-1982.

Miyoshi, H., K. Shimizu, T. Kozu, N. Maseki, Y. Kaneko, and M. Ohki. 1991. $t\{8 ; 21)$ breakpoints on chromosome 21 in acute myeloid leukemia are clustered within a limited region of a single gene, AMLl. Proc. Natl. Acad. Sci. 88: 10431-10434.

Miyoshi, H., T. Kozu, K. Shimizu, K. Enomoto, N. Maseki, Y. Kaneko, N. Kamada, and M. Ohki. 1993. The t $(8 ; 21)$ translocation in acute myeloid leukemia results in production of an AML-1-MTG8 fusion transcript. EMBO I. 12: 2715-2721.

Nakajima, T., A. Fukamizu, J. Takahashi, F.H. Gage, T. Fisher, J. Blenis, and M.R. Montminy. 1996. The signal-dependent coactivator CBP is a nuclear target for pp90RSK. Cell 86: 465-474.

Ogawa, E., M. Inuzuka, M. Maruyama, M. Satake, M. NaitoFujimoto, Y. Ito, and K. Shigesada. 1993a. Molecular cloning and characterization of PEBP2 $\beta$, the heterodimeric partner of a novel Drosophila runt-related DNA-binding protein PEBP2 $\alpha$. Virology 194: 314-331.

Ogawa, E., M. Maruyama, H. Kagoshima, M. Inuzuka, J. Lu, M. Satake, K. Shigesada, and Y. Ito. 1993b. PEBP2/PEA2 represents a family of transcription factors homologous to the products of the Drosophila runt gene and the human AMLl gene. Proc. Nat1. Acad. Sci. 90: 6859-6863.

Ogryzko, V.V., R.L. Schiltz, V. Russanova, B.H. Howard, and Y. Nakatani. 1996. The transcriptional coactivators p300 and CBP are histone acetyltransferases. Cell 87: 953-959.
Okuda, T., J. van Deursen, S.W. Hiebert, G. Grosveld, and J.R. Downing. 1996. AML1, the target of multiple chromosomal translocations in human leukemia, is essential for normal fetal liver hematopoiesis. Cell 84: 321-330.

Oosterwegel, M., M. van der Wetering, J. Timmerman, A. Kruisbeek, O. Destree, F. Meijlink, and H. Clevers. 1993. Differential expression of the HMG box factors TCF- 1 and LEF-1 during murine embryogenesis. Development 118: 439-448.

Pazin, M.J., R.T. Kamakaka, and J.T. Kadonaga. 1994. ATP-dependent nucleosome reconfiguration and transcriptional activation from preassembled chromatin templates. Science 266: 2007-2011.

Pazin, M.J., P.L. Sheridan, K. Cannon, Z. Cao, J.G. Keck, J.T. Kadonaga, and K.A. Jones. 1996. NF-кB-mediated chromatin reconfiguration and transcriptional activation of the HIV-1 enhancer in vitro. Genes \& Dev. 10: 37-49.

Satake, M., S. Nomura, Y. Yamaguchi-Iwai, Y. Takahama, Y. Hashimoto, M. Niki, Y. Kitamura, and Y. Ito. 1995. Expression of the runt domain-encoding PEBP $2 \alpha$ genes in T cells during thymic development Mol. Cell. Biol. 15: 1662-1670.

Sheridan, P.L., C.T. Sheline, K. Cannon, M.L. Voz, M.J. Pazin, J.T. Kadonaga, and K.A. Jones. 1995. Activation of the HIV-1 enhancer by the LEF-1 HMG protein on nucleosome-assembled DNA in vitro. Genes \& Dev. 9: 2090-2104.

Travis, A., A. Amsterdam, C. Belanger, and R. Grosschedl. 1991. LEF-1, a gene encoding a lymphoid-specific protein with an HMG domain, regulates T-cell receptor alpha enhancer function. Genes \& Dev. 5: 880-894.

Tsukiyama, T., P.B. Becker, and C. Wu. 1994. ATP-dependent nucleosome disruption at a heat shock promoter mediated by binding of GAGA transcription factor. Nature 367: 525-532.

Van Genderen, C., R. Okamura, I. Farinas, R. Quo, T. Parslow, L. Bruhn, and R. Grosschedl. 1994. Development of several organs that require inductive epithelial-mesenchymal interactions is impaired in LEF-1 deficient mice. Genes \& Dev. 8: 2691-2703.

Wang, S. and N.A. Speck. 1993. Purification of core-binding factor, a protein that binds the conserved core site in murine leukemai virus enhancers. Mol. Cell. Biol. 12: 89-102.

Waterman, M.L. and K.A. Jones. 1990. Purification of TCF- $1 \alpha$, a T-cell-specific transcription factor that activates the T-cell receptor $\mathrm{C} \alpha$ gene enhancer in a context-dependent manner. New Biol. 2: 621-636.

Waterman, M.L., W.H. Fischer, and K.A. Jones. 1991. A thymusspecific member of the HMG protein family regulates the human $\mathrm{T}$ cell receptor C alpha enhancer. Genes \& Dev. 5: 656-669.

Winoto, A. and D. Baltimore. 1989. A novel, inducible and T cell-specific enhancer located at the $3^{\prime}$ end of the $\mathrm{T}$ cell receptor $\alpha$ locus. EMBO I. 8: 729-733.

Wotton, D., J. Ghysdael, S. Wang, N.A. Speck, and M.J. Owen. 1994. Cooperative binding of Ets-1 and core binding factor to DNA. Mol. Cell. Biol. 14: 840-850.

Xing, I., D.D. Ginty, and M.E. Greenberg. 1996. Coupling of the RAS-MAPK pathway to gene activation by RSK2, a growth factor-regulated CREB kinase. Science 273: 959-963.

Yamamoto, K.K., G.A. Gonzalez, W.H. Biggs III, and M.R. Montminy. 1988. Phosphorylation-induced binding and transcriptional efficacy of nuclear factor CREB. Nature 334: 494-498. 


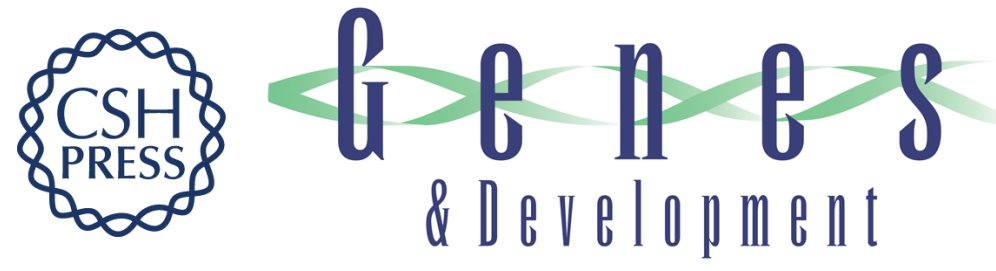

\section{Distinct roles for P-CREB and LEF-1 in TCR alpha enhancer assembly and activation on chromatin templates in vitro.}

T P Mayall, P L Sheridan, M R Montminy, et al.

Genes Dev. 1997, 11:

Access the most recent version at doi:10.1101/gad.11.7.887

References This article cites 53 articles, 26 of which can be accessed free at:

http://genesdev.cshlp.org/content/11/7/887.full.html\#ref-list-1

License

Email Alerting

Service

Receive free email alerts when new articles cite this article - sign up in the box at the top right corner of the article or click here.

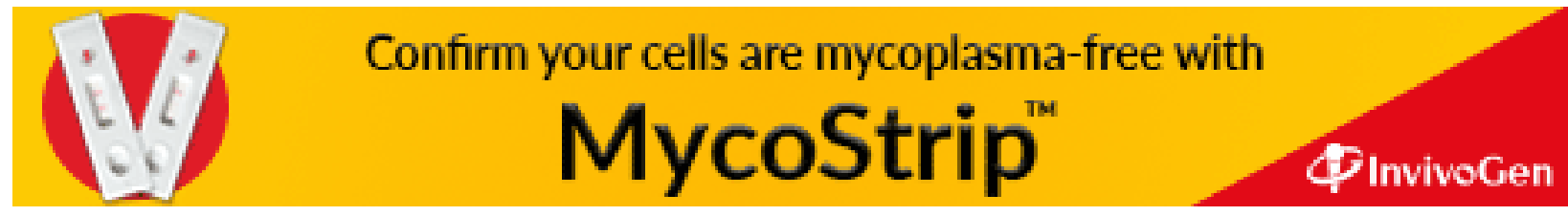

